\author{
HERMAEA \\ GERMANISTISCHE FORSCHUNGEN \\ NEUE FOLGE \\ HERAUSGEGEBEN VON \\ JOACHIM HEINZLE UND KLAUS-DETLEF MÜLLER
}

BAND 103 



\section{Fremde Historien}

Untersuchungen zur Überlieferungs- und

Rezeptionsgeschichte französischer Erzählstoffe im deutschen Spätmittelalter

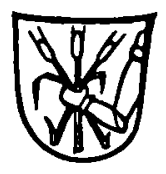

MAX NIEMEYER VERLAG TÜBINGEN 2004 
Gedruckt mit Unterstützung des

Förderungs- und Beihilfefonds Wissenschaft der VG Wort

Bibliografische Information der Deutschen Bibliothek

Die Deutsche Bibliothek verzeichnet diese Publikation in der Deutschen Nationalbibliografie; detaillierte bibliografische Daten sind im Internet über $h t t p: / / d n b . d d b . d e$ abrufbar.

ISBN 3-484-15103-X ISSN 0440-7164

(C) Max Niemeyer Verlag GmbH, Tübingen 2004

http://www.niemeyer.de

Das Werk einschließlich aller seiner Teile ist urheberrechtlich geschützt. Jede Verwertung außerhalb der engen Grenzen des Urheberrechtsgesetzes ist ohne Zustimmung des Verlages unzulässig und strafbar. Das gilt insbesondere für Vervielfältigungen, Übersetzungen, Mikroverfilmungen und die Einspeicherung und Verarbeitung in elektronischen Systemen. Printed in Germany.

Gedruckt auf alterungsbeständigem Papier.

Satz und Druck: AZ Druck und Datentechnik GmbH, Kempten

Buchbinder: Geiger, Ammerbuch 